\title{
Association of temperament and social behavior with oxytocin levels among toddlers
}

\author{
Takeo Fujiwara ${ }^{1,2^{*}}$, Manami Ochi ${ }^{1,2}$ and Maiko Osawa ${ }^{1}$ \\ *Correspondence: fujiwara-tk@ncchd.go.jp

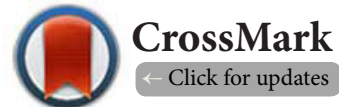 \\ 'Department of Social Medicine, National Research Institute for Child Health and Development, Tokyo, Japan. \\ ${ }^{2}$ Department of Developmental Social Medicine, Mie University Graduate School of Medicine, Mie, Japan.
}

\begin{abstract}
Background: Children with poor communication skills, such as autism, are known to have lower levels of oxytocin. However, reports on the association between social behavior and oxytocin levels in children are scarce. Similarly, few studies have shown the association between child temperament and oxytocin levels. The purpose of this study was to investigate the association of child temperament and social behavior with levels of oxytocin.

Methods: Urine samples from 23 healthy Japanese children (13 boys, 10 girls) aged 23-48 months were used to measure oxytocin levels. Temperament and behavior were assessed using the Toddler Temperament Scale (TTS) and the Strength and Difficulty Questionnaire (SDQ), respectively. The association of temperament and behavior with levels of oxytocin were analyzed.

$\underline{\text { Results: }}$ A child's persistence temperament was significantly inversely associated with oxytocin (Pearson's correlation ( $\mathrm{r}$ ) $=-0.52$, $\mathrm{p}=0.01$ ), and remained significant even after adjusted for covariates (partial correlation $=-0.63, \mathrm{p}=0.007$ ). Among SDQ subscales, peer problems were inversely associated $(\mathrm{r}=-0.60, \mathrm{p}=0.002)$, while prosocial behavior was positively associated $(\mathrm{r}=0.53, \mathrm{p}=0.01)$ with oxytocin, although the associations became weaker after adjusting for covariates. Other TTS and SDQ subscales were not associated with oxytocin.

Conclusion: A child's persistence temperament and behavior related to peer problems were inversely associated with oxytocin levels, while prosocial behavior was positively associated with oxytocin levels. Further research is needed to elucidate the mechanism of child temperament and behavior via oxytocin.
\end{abstract}

Keywords: Oxytocin, temperament, prosocial behavior, difficult behavior, toddlers, autistic spectrum disorders

\section{Introduction}

Oxytocin (OT) is known to be associated with social behavior $[1,2]$ including romantic love [3,4], parenting [5-7], and trust [8,9] in adults. Other studies have investigated the association between social behavior and circulating OT levels among children with autism spectrum disorders $[10,11]$ or schizophrenia [12]. Further, several studies reported the effectiveness of intranasal application of OT to improve social behavior among autism spectrum disorders or schizophrenia, in which social behavior is a central role [13-17]. However, to the best of our knowledge, few studies have investigated the association between OT and social behaviors among healthy children, especially toddlers.

As social behavior is associated with OT or related genes $[10,11,18-21]$, it is reasonable to hypothesize that temperament might be associated with OT levels because of the robust association between temperament and behavior [22]. Thomas and Chess were aware of the nine dimensions of temperament, which include activity, regularity, initial reaction, adaptability, intensity, mood, distractibility, persistence, attention span and sensitivity, which they based their interviews with parents of infants on [23]. Meanwhile, Rothbart and Derryberry defined temperament as individual differences in emotional, motor and attentional reactivity [24], with these biologically based differences linked to an individual's genetic endowment [25]. Recent studies have revealed that oxytocin-receptor gene variations were associated with autism spectrum disorders $[18,19]$ and children's aggressive behavior $[20,21]$. Based on that, certain genetic components related to temperament may be associated with OT-related genetic components $[7,18,19]$, and studying them could provide further insight into the developmental mechanism of temperament. Although limited to adult samples, Tost et al., have in fact reported that a common allele in the OT receptor gene was associated with prosocial temperament [26]. In order to avoid the influence of environmental factors on temperament, it is necessary to investigate the association between temperament and OT levels in children of a young age, such as toddlers.

The purpose of this study was to investigate the association of temperament and social behavior with oxytocin levels among toddlers.

\section{Materials and methods Participants}

The study was approved by the Ethics Committee of the 
Fujiwara et al. Paediatrics and Health 2014,

National Institute for Public Health. All participants signed informed consent forms prior to enrollment in the study. 52 mothers with 18-48-month-old children were recruited through snowball sampling (from personal connections of research coordinators or the participants themselves). All participants were Japanese living in greater Tokyo. Urine samples were successfully collected from 23 healthy children with no diagnosed developmental disability.

\section{OT level analysis}

Research coordinators visited each participant's home for approximately an hour between 11 a.m. and 2 p.m. Urine samples were obtained from the children as the collection procedure is noninvasive and easy to conduct. A $1 \mathrm{~mL}$ urine sample from each child was collected in a tube to which a $40 \mu \mathrm{L}$ aliquot of sodium citrate buffer $(0.03 \mathrm{M}$ sodium citrate, $25 \mathrm{mM}$ EDTA and $0.35 \mathrm{mM}$ 1,10-phenanthroline) was added. Samples were stored immediately in a cooler box at $4^{\circ} \mathrm{C}$ for a maximum of two hours, and later kept at $-20^{\circ} \mathrm{C}$ in the laboratory.

OT concentrations in the urine samples were measured by a competitive radioimmunoassay as described elsewhere [27]. Measurement of urinary OT per mg of creatinine showed a strong correlation with plasma OT measurements in a previous study ( $r=0.89)$ [28]. Briefly, rabbit antiserum specific for human OT was generated by immunizing a rabbit four times with recombinant human OT (ASKA Pharmaceutical. Co., Ltd., Tokyo, Japan) conjugated with water-soluble carbodiimide (Nakarai Tesque, Tokyo, Japan). Urine samples were decomplemented at $56^{\circ} \mathrm{C}$ for $30 \mathrm{~min}$, with the supernatant extracted after centrifugation $\left(3,000 \mathrm{rpm}, 10 \mathrm{~min}, 4^{\circ} \mathrm{C}\right)$. An equal amount of decomplemented sample and ${ }^{125}$-labeled OT (Perkin Elmer Life Sciences, Inc., Boston MA) solution were allocated for use in an assay tube (Shionogi, Tokyo, Japan). Rabbit antiOT serum was then added to each assay tube followed by incubation for two days at $4^{\circ} \mathrm{C}$. Subsequently, goat anti-rabbit IgG serum (ASKA Pharmaceutical. Co., Ltd., Tokyo, Japan) was added to each assay tube followed by incubation for one day at $4^{\circ} \mathrm{C}$. After centrifugation, radioreactivity of the pellet was measured by a gamma counter (Auto Well Gamma System ARC-1000M, Aloka, Tokyo Japan). According to a standard curve, the minimal detection limit of the assay was $3 \mu \mathrm{U} / \mathrm{mL}$ (1 $\mu \mathrm{U}$ of OT is equivalent to $1.776 \mathrm{pg}$ ). All assays were performed in duplicate. The assay's intra- and inter-assay coefficients of variability were $<14.2 \%$. The concentration of OT in the urine was standardized according to the urinary creatinine concentration. Urinary creatinine was measured using the alkaline picrate colorimetric method (modified Jaffe).

\section{Assessment of temperament and social behavior}

A questionnaire, composed of 62 items and to be completed by the mothers, was sent out prior to the home visit and was collected in person. Each child's temperament was assessed using the Japanese version of the Toddler Temperament Scale
(TTS). The TTS was originally developed in the USA [29] and the Japanese version has been validated [30]. The item response is a 6-Lickert scale from 'hardly never' to 'almost always'. Factor analysis of the Japanese version of TTS revealed the following seven factors (rather than the original nine factors suggested by Thomas and Chess which have a 32\% cumulative contribution ratio): fear of strangers and strange situation (defined as initial response to new things or situations), 13 items; frustration tolerance (defined as ability to accept frustrating situation), 10 items; regularity (defined as predictability of biological functions such as eating, sleeping, etc.), 9 items; visual and auditory sensitivity (defined as how sensitive to physical stimuli such as light or sound), 9 items; intensity (defined as the energy level of one's emotional response both positive and negative situations), 7 items; attention span and persistence (defined as the length of time with continued attention or performing a specific activity without feeling bored), 8 items; and sensitivity of taste and touch (level of response to physical stimuli such as taste and texture), 6 items. Chronbach's alpha of each subscale showed valid internal consistency (range, 0.71-0.95), excluding sensitivity of taste and touch (alpha= 0.57 ). Thus, the remaining six factors, calculated as the mean of the items therein, were used for analysis (i.e., ranged 1-6).

Social behavior of each child was assessed using the Strength and Difficulty Questionnaire (SDQ), through a questionnaire completed by the mother. The SDQ is a 25 -item measure of the parents' perceptions of prosocial, defined as voluntary behavior that benefits others or promotes harmonious relations with others [31], as well as difficult behaviors of their children [32]. The SDQ consists of five subscales (emotional symptoms, conduct problems, hyperactivity, peer problems and prosocial behavior) and the score for each subscale is computed by summing the scores for the five items. The difficult behavior score in the SDQ is calculated as the sum of the scores obtained for the emotional symptoms, conduct problems, hyperactivity, and peer problems subscales. The SDQ in Japanese has been validated as having adequate internal reliability (emotional symptoms, 0.61 ; conduct problems, 0.51 ; hyperactivity, 0.75 ; peer problems, 0.52 ; and prosocial behavior, 0.69) [33]. Additionally, the difficult behavior score has been found to have adequate internal reliability $(r=0.76)$ and good test-retest reliability $(r=0.85)$ [34].

\section{Statistical analysis}

TTS and SDQ score calculation were performed before obtaining the OT result, eliminating the influence by the results on OT levels. First, the associations between demographic, psychosocial, environmental and familial characteristics (age, sex, number of siblings, attendance of preschool or day care, having a friend to play with regularly, and annual household income), and OT levels were investigated using $t$-test analysis. Further, associations of the TTS and SDQ subscales with urinary OT levels were analyzed using Pearson's correlation, including bivariate models to determine both the crude association and 
Fujiwara et al. Paediatrics and Health 2014,

partial correlation while excluding the effect of covariates (i.e., controlled for environmental and familial characteristics). All analyses were performed using the STATA MP version 12.0 software package (STATA Corporation, College Station, TX 2011).

\section{Results}

\section{Characteristics of the children}

(Table 1) The mean age was 38.3 months (standard deviation [SD], 6.2; range, 23-48 months). Sex ratio was almost identical (13 boys; $56.5 \%$ ). The mean number of siblings was 0.7 (SD, 0.8 ); more precisely, there were no siblings in 12 cases (52.2\%), one sibling in seven cases (30.4\%), and two siblings in four cases (17.4\%). Around $70 \%$ of the children $(n=16)$ attended preschool or day care, and $87 \%(n=20)$ had friend/s to play with regularly. About $70 \%(n=16)$ were living in a family with

Table 1. Characteristics of sample.

\begin{tabular}{|c|c|c|c|}
\hline Characteristics & & $\mathbf{N}$ & $\%$ \\
\hline \multirow[t]{2}{*}{ Age (month) } & $23-36$ & 8 & 34.8 \\
\hline & $37-48$ & 15 & 65.2 \\
\hline \multirow[t]{2}{*}{ Sex } & Boy & 13 & 56.5 \\
\hline & Girl & 10 & 43.5 \\
\hline \multirow[t]{3}{*}{ Number of sibling } & 0 & 12 & 52.2 \\
\hline & 1 & 7 & 30.4 \\
\hline & 2 & 4 & 17.4 \\
\hline \multirow[t]{2}{*}{ Attending preschool or day care } & Yes & 16 & 69.6 \\
\hline & No & 7 & 30.4 \\
\hline \multirow{2}{*}{$\begin{array}{l}\text { Having friend/s to play with } \\
\text { regularly }\end{array}$} & Yes & 20 & 87.0 \\
\hline & No & 3 & 13.0 \\
\hline \multirow[t]{5}{*}{$\begin{array}{l}\text { Annual household income } \\
\text { (million yen) }\end{array}$} & $\leq 6$ & 6 & 26.1 \\
\hline & $6.1-10$ & 11 & 47.8 \\
\hline & $10+$ & 4 & 17.4 \\
\hline & Refuse to answer & 2 & 8.7 \\
\hline & & Mean & SD \\
\hline \multirow[t]{6}{*}{ Temperament } & $\begin{array}{l}\text { Fear of strangers and } \\
\text { strange situation }\end{array}$ & 4.06 & 1.18 \\
\hline & Frustration tolerance & 3.86 & 0.92 \\
\hline & Regularity & 4.55 & 0.59 \\
\hline & $\begin{array}{l}\text { Visual and auditory } \\
\text { sensitivity }\end{array}$ & 4.42 & 0.65 \\
\hline & Intensity & 3.07 & 0.99 \\
\hline & $\begin{array}{l}\text { Attention span and } \\
\text { persistence }\end{array}$ & 4.87 & 0.59 \\
\hline \multirow[t]{5}{*}{ Behaviors } & Emotional symptoms & 8.96 & 1.02 \\
\hline & Conduct problems & 7.83 & 2.01 \\
\hline & $\begin{array}{l}\text { Hyperactivity/ } \\
\text { inattention }\end{array}$ & 7.83 & 1.80 \\
\hline & Peer problems & 8.61 & 1.83 \\
\hline & Prosocial behavior & 3.35 & 2.64 \\
\hline
\end{tabular}

an annual household income of more than six million yen, suggesting relatively affluent socioeconomic background.

\section{Urinary OT levels}

(Table 2) OT levels were slightly skewed to the right, with a mean of 179.5 (SD, 78.1; range, 78.5-412.8). The children's urinary OT level was inversely associated with age $(r=-0.66, p=0.006)$, i.e., younger child showed higher urinary OT levels. Further, OT level was higher in boys than in girls ( 207.3 vs. $143.5 \mu \mathrm{U} / \mathrm{mL}$ per creatinine $g / L, t=2.08, p=0.0497$ ). The number of children per household was not significantly associated with OT levels, although those having siblings showed lower OT levels $(p=0.12)$. Having regular friends to play with is significantly associated with lower OT level as opposed to those who do not (158.5 vs. 319.7, $t=4.63, p=0.0001$ ). Attendance of preschool or day

Table 2. Urinary oxytocin level for total and subgroup.

\begin{tabular}{lcccl}
\hline & & Mean & \multicolumn{1}{l}{ SD } & p \\
\hline Total & -- & 179.5 & 78.1 & -- \\
\hline Age (month) & $23-36$ & 229.8 & 101.4 & $\mathbf{0 . 0 2}$ \\
& $37-48$ & 152.7 & 47.4 & -- \\
\hline Sex & Boy & 207.3 & 76.6 & $\mathbf{0 . 0 4 9 7}$ \\
& Girl & 143.5 & 67.5 & -- \\
\hline Number of sibling & 0 & 203.6 & 84.0 & 0.12 \\
& $1+$ & 153.2 & 64.9 & -- \\
\hline Attending preschool or day care & Yes & 176.2 & 63.1 & 0.76 \\
& No & 187.2 & 111.0 & -- \\
\hline Having friend/s to play with regularly & Yes & 158.5 & 52.1 & $<\mathbf{0 . 0 0 1}$ \\
& No & 319.7 & 86.6 & -- \\
\hline Annual household income (million yen) & $\leq 6$ & 122.4 & 35.7 & 0.10 \\
& $6.1-10$ & 202.2 & 85.6 & -- \\
& $10+$ & 206.5 & 74.7 & -- \\
\hline
\end{tabular}

unit: $\mu \mathrm{U} / \mathrm{ml}$ per creatinine $\mathrm{g} / \mathrm{L}$

care and annual household income was not associated with children's urinary OT level.

Association between demographic characteristics and TTS or SDQ subscales

Older toddlers had more peer problems and fewer prosocial behaviors than younger toddlers; boys had more conduct problems, fewer peer problems, and more prosocial problems than girls; and toddlers having siblings had fewer conduct problems, more hyperactivity, and more peer problems than those without siblings, although not statistically significant.

Pearson's correlations between TTS subscales and OT levels (Table 3) In the crude model, the attention span and persistence subscale was significantly inversely associated with OT levels 
Fujiwara et al. Paediatrics and Health 2014,

$(r=-0.52, p=0.011$; Figure 1). Further, in partial correlation, the attention span and persistence subscale remained significantly associated with OT levels ( $r=-0.63, p=0.007)$. Other TTS subscales (fear, frustration tolerance, regularity, visual and auditory sensitivity and intensity) were not significantly associated with OT levels.

Table 3. Pearson's correlation between toddler's temperament subscales and urinary oxytocin levels.

\begin{tabular}{lclcl}
\hline Temperament subscales & $\begin{array}{c}\text { Crude } \\
\mathbf{R}\end{array}$ & $\mathbf{p}$ & $\begin{array}{c}\text { Partial } \\
\mathbf{R}^{*}\end{array}$ & $\mathbf{p}$ \\
\hline Fear of strangers and strange situation & 0.10 & 0.66 & 0.0015 & $>0.99$ \\
Frustration tolerance & 0.09 & 0.67 & -0.21 & 0.41 \\
Regularity & -0.10 & 0.67 & -0.44 & 0.08 \\
Visual and auditory sensitivity & -0.04 & 0.84 & -0.44 & 0.08 \\
Intensity & -0.18 & 0.42 & -0.10 & 0.70 \\
Attention span and persistence & $\mathbf{- 0 . 5 2}$ & $\mathbf{0 . 0 1 1}$ & $\mathbf{- 0 . 6 3}$ & $\mathbf{0 . 0 0 7}$ \\
\hline
\end{tabular}

${ }^{*}$ Controlled for age, sex, number of siblings, preschool attendance, having regular friend, and household income.

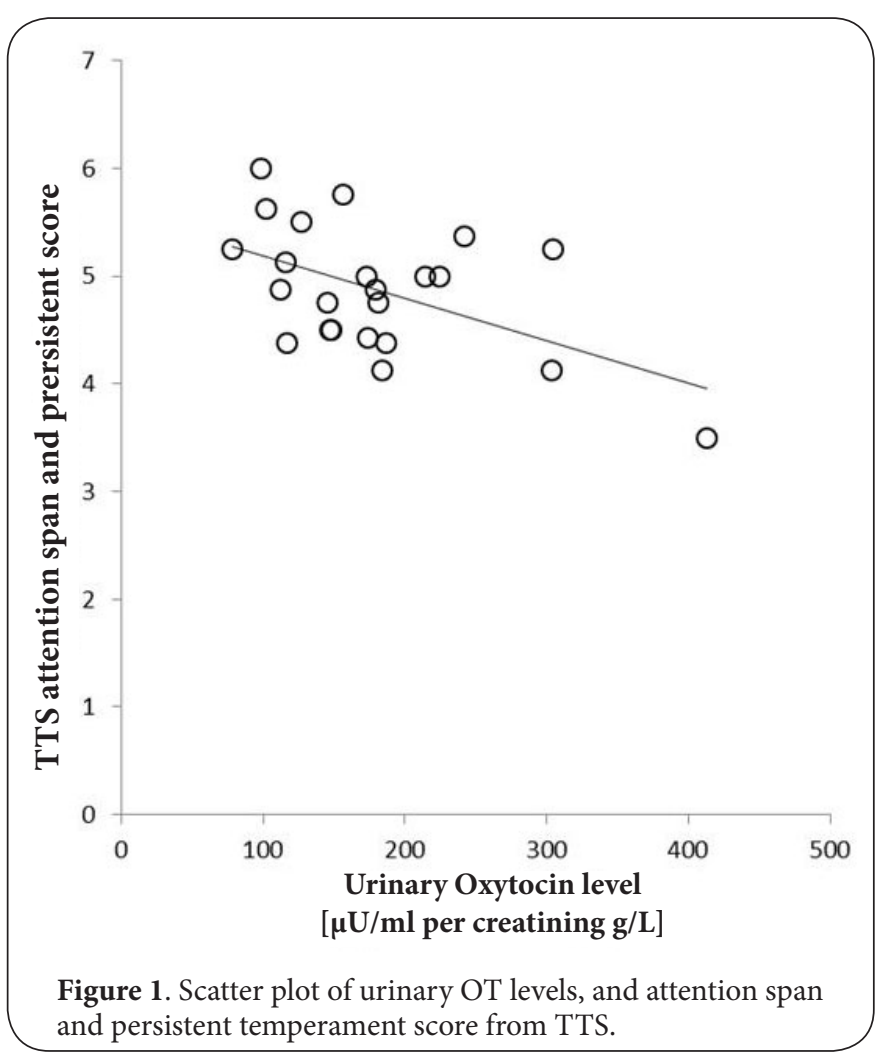

Pearson's correlation between SDQ subscales and OT levels (Table 4) In the crude model, peer problems were inversely associated ( $r=-0.60, p=0.002$; Figure 2 ), while prosocial behavior was positively associated ( $r=0.53, p=0.0097$; Figure 2 ), with OT levels. However, in the partial correlation model, the associations became weaker after the adjustment of demographic characteristics. More specifically, while they remained significant when adjusted for sex and number of siblings (peer problems: $r=-0.52, p=0.016$; prosocial behavior: $r=0.57, p=0.007)$, they lost their significance after including age (peer problems: $r=-0.30, p=0.21$; prosocial behavior: $r=$ $0.31, p=0.19$ ) and other covariates (peer problems: $r=-0.28, p=$ 0.27 ; prosocial behavior: $r=0.21, p=0.42$ ). Other $S D Q$ subscales (emotional symptoms, conduct problems and hyperactivity/ inattention) and total scale as difficult behaviors were not associated with OT.

Table 4. Pearson's correlation between toddler's SDQ subscales and urinary oxytocin levels.

\begin{tabular}{lllll}
\hline SDQ subscales & Crude $\mathbf{R}$ & $\mathbf{p}$ & Partial $\mathbf{R}^{*}$ & $\mathbf{p}$ \\
\hline Emotional symptoms & 0.06 & 0.80 & 0.13 & 0.62 \\
Conduct problems & 0.10 & 0.66 & -0.31 & 0.23 \\
Hyperactivity/inattention & -0.15 & 0.49 & -0.24 & 0.36 \\
Peer problems & $\mathbf{- 0 . 6 0}$ & $\mathbf{0 . 0 0 2}$ & -0.28 & 0.27 \\
Prosocial behavior & $\mathbf{0 . 5 3}$ & $\mathbf{0 . 0 0 9 7}$ & 0.21 & 0.42 \\
\hline
\end{tabular}

SDQ: Strength and Difficulty Questionnaire

${ }^{*}$ controlled for age, sex, number of siblings, preschool attendance, having regular friend, and household income.

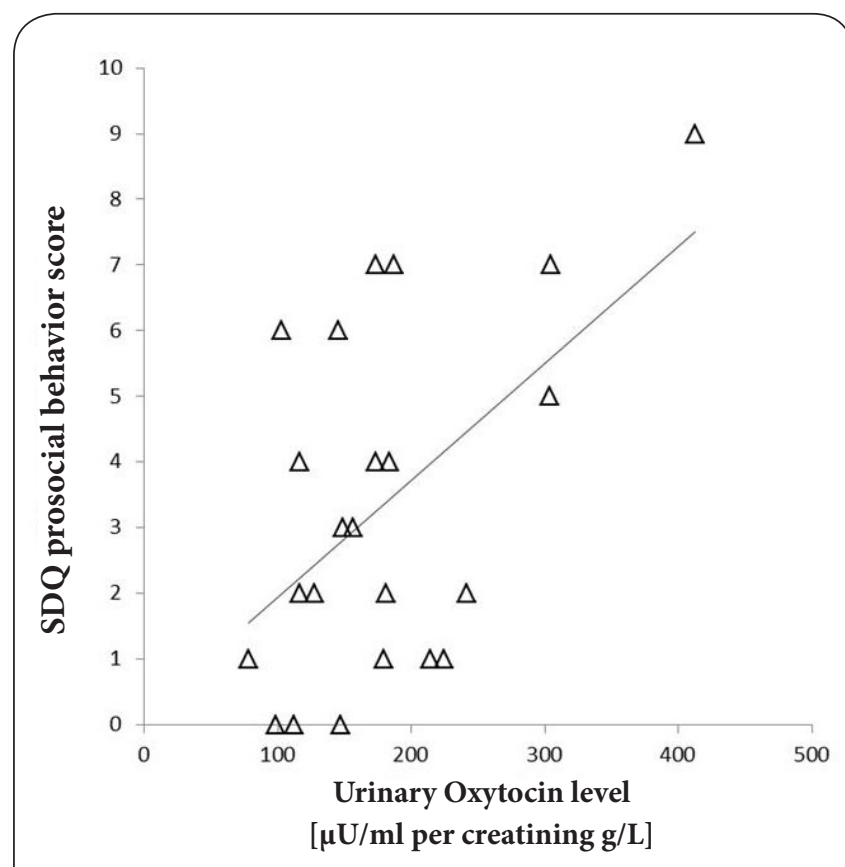

Figure 2. Scatter plot of urinary OT levels and prosocial behavior score from SDQ. 
Fujiwara et al. Paediatrics and Health 2014,

\section{Discussion}

Our findings suggest that OT level is associated with toddler's attention span and persistence temperament, although the directionality (i.e., whether low OT induces attention span and persistence temperament or such a temperament is less likely to produce OT) is unknown.

To the best of our knowledge, this is the first study to report on the association between OT levels and toddler's temperament and behavior. It has been reported that children with autism showed lower plasma OT levels $[10,11]$ than children without autism. Our findings are in line with these previous studies, as autistic traits include persistency. Moreover, we have added to the literature that children with higher scores on attention span and persistence, even if not diagnosed with autism spectrum disorder, showed lower OT levels. Although directionality is unknown, it is reasonable to assume that toddlers with longer attention span and persistence temperament are less likely to produce OT as temperament is considered to be innate [25]. The genetic endowment related to attention span and persistence temperament are most likely to be associated with OT related genes, such as oxytocin receptor genes (rs2254298 and rs 1042778) or CD38 (rs3796863) [7].

Our results are also consistent with that of previous studies showing the association between OT and prosocial behavior in adults. For example, intranasal OT administration increases both trust and empathy, and improves the capacity to read subtle non-verbal signals allowing individuals to understand the intentions and behavior of social partners [35]. Our study shows that the association between OT and prosocial behavior is found even in toddlers. Thus, intervention such as intensive parental involvement may increase OT levels in toddlers, enhancing prosocial behavior [36]. However, further randomized controlled trials to prove this hypothesis are needed.

Our study showed an inverse association between OT levels and peer problems, while other subscales of SDQ had no association with levels of OT. One possible explanation for this difference is that lower OT levels induce poor social interaction, causing peer problems. A previous study showed that peer problems were significantly inversely correlated with prosocial behavior $(r=-0.19, p<0.0001)$ [33], which is consistent with our results. Meanwhile, the lack of association between OT and emotional problem is inconsistent from the previous study showing the effectiveness of intranasal OT on emotion recognition for youth with autism spectrum disorders [37]. In healthy toddlers, association between OT and emotion might be weaker than in children with autistic spectrum disorders. Further study is needed to elucidate how emotion and behaviors interact with OT among healthy children [35].

Several limitations need to be addressed before drawing firm conclusions. First, the participants were recruited through personal connection with one of the authors. This precludes the generalizability of the findings. To lessen the impact of this limitation, our samples were selected from various locations in greater Tokyo and covered a wide range of temperament and social behavior. Second, we used spot urine samples as a proxy of circulating OT levels. However, urinary OT levels may be different from plasma OT, saliva OT (i.e., peripheral OT) or cerebrospinal fluid OT (i.e., central OT) [6,38]. A further study is needed to replicate these findings using other OT measurements to determine whether other measurement methods may yield different results. Nonetheless, in animal models, urinary oxytocin assays have been reported to be a valid biomarker [39]. Third, our cross-sectional design precludes conclusions about the causal relationship between OT levels and temperament or social behavior, particularly if higher OT causes social behavior or vice versa. Also, a toddler's temperament or social behavior can be influenced by parenting during infancy, and parenting for toddlers can be influenced by temperament or social behavior during infancy. Previous longitudinal findings suggested a mutually influencing biobehavioral process where a child's OT levels are shaped by the parent's behavior in early toddlerhood, which is predicted by their OT levels, and the parents' early behavior predicts the reciprocal dialog and empathy with which children make friendly attachments to non-kin members of society $[40,41]$. Again, a future prospective study is needed to confirm whether circulating OT levels predict social behavior.

\section{Conclusion}

In toddlers, attention span and persistence temperament, as well as behavior related to peer problems, were inversely associated with OT levels, while prosocial behavior was positively associated with OT levels. Further longitudinal study is needed to elucidate whether infant temperament determine OT levels, and whether OT levels during infancy determine social behaviors during toddler age.

\section{Competing interests}

The authors declare that they have no competing interests.

Authors' contributions

\begin{tabular}{|l|c|c|c|}
\hline Authors' contributions & TF & M01 & M02 \\
\hline Research concept and design & $\checkmark$ & -- & -- \\
\hline Collection and/or assembly of data & -- & -- & $\checkmark$ \\
\hline Data analysis and interpretation & $\checkmark$ & -- & -- \\
\hline Writing the article & $\checkmark$ & $\checkmark$ & -- \\
\hline Critical revision of the article & $\checkmark$ & $\checkmark$ & -- \\
\hline Final approval of article & $\checkmark$ & $\checkmark$ & $\checkmark$ \\
\hline Statistical analysis & $\checkmark$ & -- & -- \\
\hline
\end{tabular}

\section{Acknowledgement}

We thank Ms Hanako Fujiwara, who collected sample from the participants through home visits. We are grateful for all the participants and their family. We would also like to thank Dr. Julian Tang, National Center for Child Health and Development, for proofreading and editing this manuscript. 
Fujiwara et al. Paediatrics and Health 2014,

http://www.hoajonline.com/journals/pdf/2052-935X-2-2.pdf

doi: 10.7243/2052-935X-2-2

This research was supported by Research Development Grant for Child Health and Development from National Center for Child Health and Development (21 shi -10 and 24-12).

Publication history

Editors: Stephen R. Bates, University of Arkansas for Medical

Sciences, USA.

Ozgur Duman, Akdeniz University Hospital, Turkey.

Received: 02-Dec-2013 Revised: 08-Jan-2014

Re-Revised: 17-Jan-2014 Accepted: 21-Jan-2014

Published: 29-Jan-2014

\section{References}

1. Bartz JA and Hollander E. The neuroscience of affiliation: forging links between basic and clinical research on neuropeptides and social behavior. Horm Behav. 2006; 50:518-28. I Article I PubMed

2. Heinrichs $M$, von Dawans $B$ and Domes $G$. Oxytocin, vasopressin, and human social behavior. Front Neuroendocrinol. 2009; 30:548-57. I Article I PubMed

3. Gonzaga GC, Turner RA, Keltner D, Campos B and Altemus M. Romantic love and sexual desire in close relationships. Emotion. 2006; 6:163-79. I Article | PubMed

4. de Boer A, van Buel EM and Ter Horst GJ. Love is more than just a kiss: a neurobiological perspective on love and affection. Neuroscience. 2012; 201:114-24. | Article | PubMed

5. Feldman R, Weller A, Zagoory-Sharon O and Levine A. Evidence for a neuroendocrinological foundation of human affiliation: plasma oxytocin levels across pregnancy and the postpartum period predict motherinfant bonding. Psychol Sci. 2007; 18:965-70. | Article | PubMed

6. Feldman R, Gordon I and Zagoory-Sharon O. Maternal and paternal plasma, salivary, and urinary oxytocin and parent-infant synchrony: considering stress and affiliation components of human bonding. Dev Sci. 2011; 14:752-61. | Article | PubMed

7. Feldman R, Zagoory-Sharon O, Weisman O, Schneiderman I, Gordon I, Maoz R, Shalev I and Ebstein RP. Sensitive parenting is associated with plasma oxytocin and polymorphisms in the OXTR and CD38 genes. Biol Psychiatry. 2012; 72:175-81. | Article | PubMed

8. Fujiwara T, Kubzansky LD, Matsumoto K and Kawachi I. The association between oxytocin and social capital. PLoS One. 2012; 7:e52018. | Article | PubMed Abstract | PubMed Full Text

9. Kosfeld M, Heinrichs M, Zak PJ, Fischbacher U and Fehr E. Oxytocin increases trust in humans. Nature. 2005; 435:673-6. | Article | PubMed

10. Modahl C, Green L, Fein D, Morris M, Waterhouse L, Feinstein C and Levin H. Plasma oxytocin levels in autistic children. Biol Psychiatry. 1998; 43:270-7. | $\underline{\text { Article | PubMed }}$

11. Hammock E, Veenstra-VanderWeele J, Yan Z, Kerr TM, Morris M, Anderson GM, Carter CS, Cook EH and Jacob S. Examining autism spectrum disorders by biomarkers: example from the oxytocin and serotonin systems. J Am Acad Child Adolesc Psychiatry. 2012; 51:712721. | Article | PubMed Abstract | PubMed Full Text

12. Sasayama D, Hattori K, Teraishi T, Hori H, Ota M, Yoshida S, Arima K, Higuchi T, Amano $\mathrm{N}$ and Kunugi $\mathrm{H}$. Negative correlation between cerebrospinal fluid oxytocin levels and negative symptoms of male patients with schizophrenia. Schizophr Res. 2012; 139:201-6. | Article | PubMed

13. Domes G, Heinrichs M, Kumbier E, Grossmann A, Hauenstein K and Herpertz SC. Effects of intranasal oxytocin on the neural basis of face processing in autism spectrum disorder. Biol Psychiatry. 2013; 74:16471. | Article | PubMed

14. Tachibana M, Kagitani-Shimono K, Mohri I, Yamamoto T, Sanefuji W, Nakamura A, Oishi M, Kimura T, Onaka T, Ozono K and Taniike M. Longterm administration of intranasal oxytocin is a safe and promising therapy for early adolescent boys with autism spectrum disorders. J Child Adolesc Psychopharmacol. 2013; 23:123-7. | Article | PubMed

15. Kosaka H, Munesue T, Ishitobi M, Asano M, Omori M, Sato M, Tomoda
A and Wada Y. Long-term oxytocin administration improves social behaviors in a girl with autistic disorder. BMC Psychiatry. 2012; 12:110. | Article | PubMed Abstract | PubMed Full Text

16. Andari E, Duhamel JR, Zalla T, Herbrecht E, Leboyer M and Sirigu A. Promoting social behavior with oxytocin in high-functioning autism spectrum disorders. Proc Natl Acad Sci U S A. 2010; 107:4389-94. | Article | PubMed Abstract | PubMed Full Text

17. De Berardis D, Marini S, lasevoli F, Tomasetti C, de Bartolomeis A, Mazza M, Valchera A, Fornaro M, Cavuto M, Srinivasan V, Sepede G, Martinotti $\mathrm{G}$ and Di Giannantonio $M$. The role of intranasal oxytocin in the treatment of patients with schizophrenia: a systematic review. CNS Neurol Disord Drug Targets. 2013; 12:252-64. | Article I PubMed

18. Wu S, Jia M, Ruan Y, Liu J, Guo Y, Shuang M, Gong X, Zhang Y, Yang X and Zhang D. Positive association of the oxytocin receptor gene (OXTR) with autism in the Chinese Han population. Biol Psychiatry. 2005; 58:74-7. I Article | PubMed

19. Jacob S, Brune CW, Carter CS, Leventhal BL, Lord C and Cook EH, Jr. Association of the oxytocin receptor gene (OXTR) in Caucasian children and adolescents with autism. Neurosci Lett. 2007; 417:6-9. | Article | PubMed Abstract | PubMed Full Text

20. Malik AI, Zai CC, Abu Z, Nowrouzi B and Beitchman JH. The role of oxytocin and oxytocin receptor gene variants in childhood-onset aggression. Genes Brain Behav. 2012; 11:545-51. | Article I PubMed

21. Beitchman JH, Zai CC, Muir K, Berall L, Nowrouzi B, Choi E and Kennedy $\mathrm{JL}$. Childhood aggression, callous-unemotional traits and oxytocin genes. Eur Child Adolesc Psychiatry. 2012. | Article I PubMed

22. Earls F. Temperament characteristics and behavior problems in threeyear-old children. J Nerv Ment Dis. 1981; 169:367-73. I Article I PubMed

23. Thomas $A$ and Chess S. Temperament and development. New York: Brunner/Mazel; 1977. | Website

24. Rothbart MK and Derryberry D. Development of individual differences in temperament. In: Lamb ME, Brown A, editors. Advances in developmental psychology. Hillsdale, NJ: Erlbaum; 1981; 37-86. I Website

25. Posner MI, Rothbart MK and Sheese BE. Attention genes. Dev Sci. 2007; 10:24-9. | Article | PubMed

26. Tost $H$, Kolachana B, Hakimi S, Lemaitre H, Verchinski BA, Mattay VS Weinberger DR and Meyer-Lindenberg A. A common allele in the oxytocin receptor gene (OXTR) impacts prosocial temperament and human hypothalamic-limbic structure and function. Proc Natl Acad Sci U S A. 2010; 107:13936-41. | Article | PubMed Abstract | PubMed Full Text

27. Sudo T, Okumura H, Fujisawa M, Kendo M and Sawai M. [Radioimmunoassay of oxytocin]. Horumon To Rinsho. 1978; 26:179-87. | Article | PubMed

28. Amico JA, Ulbrecht JS and Robinson AG. Clearance studies of oxytocin in humans using radioimmunoassay measurements of the hormone in plasma and urine. J Clin Endocrinol Metab. 1987; 64:340-5. | Article | PubMed

29. Fullard W, McDevitt SC and Carey WB. Assessing temperament in oneto three-year-old children. J Pediatr Psychol. 1984; 9:205-17. | Article | PubMed

30. Sugawara M, Shima S, Toda M, Sato T and Kitamura T. Behavioral characterristics in early childhood - an investigation of RITQ and TTS (Japanese Version)-. Japanese. Journal of Educational Psychology. 1994; 42:315-23.

31. Bergin C, Talley S and Hamer L. Prosocial behaviours of young adolescents: a focus group study. J Adolesc. 2003; 26:13-32. | Article | PubMed

32. Goodman R. The Strengths and Difficulties Questionnaire: a research note. J Child Psychol Psychiatry. 1997; 38:581-6. | Article I PubMed

33. Matsuishi T, Nagano M, Araki Y, Tanaka Y, Iwasaki M, Yamashita Y, Nagamitsu S, lizuka C, Ohya T, Shibuya K, Hara M, Matsuda K, Tsuda A and Kakuma T. Scale properties of the Japanese version of the Strengths and Difficulties Questionnaire (SDQ): a study of infant and school children in community samples. Brain Dev. 2008; 30:410-5. I Article I PubMed

34. Smedje H, Broman JE, Hetta J and von Knorring AL. Psychometric properties of a Swedish version of the "Strengths and Difficulties 
Fujiwara et al. Paediatrics and Health 2014,

Questionnaire". Eur Child Adolesc Psychiatry. 1999; 8:63-70. | Article | PubMed

35. Bartz JA, Zaki J, Bolger $\mathrm{N}$ and Ochsner KN. Social effects of oxytocin in humans: context and person matter. Trends Cogn Sci. 2011; 15:301-9. | Article | PubMed

36. Weisman O, Zagoory-Sharon $\mathrm{O}$ and Feldman R. Oxytocin administration to parent enhances infant physiological and behavioral readiness for social engagement. Biol Psychiatry. 2012; 72:982-9. | Article | PubMed

37. Guastella AJ, Einfeld SL, Gray KM, Rinehart NJ, Tonge BJ, Lambert TJ and Hickie IB. Intranasal oxytocin improves emotion recognition for youth with autism spectrum disorders. Biol Psychiatry. 2010; 67:692-4. | Article I PubMed

38. Heim C, Young LJ, Newport DJ, Mletzko T, Miller AH and Nemeroff CB. Lower CSF oxytocin concentrations in women with a history of childhood abuse. Mol Psychiatry. 2009; 14:954-8. | Article | PubMed

39. Mitsui S, Yamamoto M, Nagasawa M, Mogi K, Kikusui T, Ohtani $N$ and Ohta $\mathrm{M}$. Urinary oxytocin as a noninvasive biomarker of positive emotion in dogs. Horm Behav. 2011; 60:239-43. | Article | PubMed

40. Gordon I, Zagoory-Sharon O, Leckman JF and Feldman R. Oxytocin and the development of parenting in humans. Biol Psychiatry. 2010; 68:37782. | Article | PubMed

41. Feldman R. Bio-behavioral Synchrony: A Model for Integrating Biological and Microsocial Behavioral Processes in the Study of Parenting. Parenting: Science and Practice. 2012; 12:154-64. | Article

\section{Citation:}

Fujiwara T, Ochi M and Osawa M. Association of temperament and social behavior with oxytocin levels among toddlers. Paediatr Health. 2014; 2:2.

http://dx.doi.org/10.7243/2052-935X-2-2 